\title{
Training Needs Assessment of Health Care Workers attached to Healthy Lifestyle Centers in Sri Lanka
}

\author{
Vindya Kumarapeli *, Sinha De Silva**, Uthpala Muhandiram*, Nimani de Lanerolle*, Dhanushka \\ Abeygunathilaka*, Casthuri Kandasamy*, Chithramali Rodrigo* \\ * Directorate of Non-Communicable Diseases, Ministry of Health, Sri Lanka \\ ** Postgraduate Institute of Medicine, University of Colombo, Sri Lanka
}

DOI: 10.31364/SCIRJ/v9.i06.2021.P0621864

http://dx.doi.org/10.31364/SCIRJ/v9.i06.2021.P0621864

Abstract-

INTRODUCTION: NCD screening and lifestyle modification counselling services are delivered through the network of healthy lifestyle centers (HLC) situated across Sri Lanka. Medical Officers (MO), Public Health Nursing Officers (PHNO), Nursing Officers (NO), and other categories provide their services at HLCs. The aim of this study was to identify the training needs of these healthcare workers (HCW).

METHOD: 125 HLCs were selected using purposive sampling in a manner to represent all the districts of the country and $132 \mathrm{HCW}$ of MO, NO, PHNO and other major staff categories employed were recruited using simple random sampling. Data was collected by using a self-administered questionnaire containing modified Hennessy-Hicks Training Needs questionnaire. Data were analyzed by using descriptive statistics. The magnitude of the training need was recognized by calculating the average difference between the importance score and performance score for each training area. The training needs were prioritized for each staff category based on the magnitude of differences in the score.

RESULTS: The response rate for the study was $91 \%(\mathrm{n}=120)$. The study participants consisted of $76(63.3 \%)$ MO, 21(17.5\%) NO, 19(15.8\%) PHNO, and $4(3.4 \%)$ and the 'other' category. When the first five prioritized training areas were considered, conducting special programs to clients on a healthy diet, physical activity, and conducting oral examination were common among MOs, NOs, and PHNOs. Both MOs and PHNOs identified conducting brief interventions for tobacco cessation as a priority training need. Furthermore, PHNOs and NOs shared the priority training need of logistics management. MOs and NOs had unique priority training needs of conducting health education sessions and conducting breast examination respectively. Training need of conducting health education session among MO was statically significant $\mathbf{p}<0.001$ compared with other staff categories.

CONCLUSION AND RECOMMENDATIONS: There are training needs at different intensities among healthcare workers. Preparation of training programs/ interventions tailormade to address these priorities health needs will serve the purpose.

Index Terms - Training Need Assessment, Healthy Lifestyle Centers, Sri Lanka.

\section{INTRODUCTION}

Training is decisive for quality improvement in health care. However, training is often provided without much planning, which happens in both developed and developing countries. A need assessment of training of all the involved parties is crucial to ensure the effectiveness of the training [1]. The training process is often portrayed as a cycle. This cycle is composed of interrelated components that are the steps of a systematic process, usually starting with needs assessment and ending with assessing learning and training evaluation [2].

The Healthy lifestyle centers were established in 2011 with a strategic program conducting cost-effective screening for noncommunicable diseases (NCDs) in Sri Lanka. There are 1005 Healthy lifestyle centers established within the country providing universal health coverage through patient-centered management of NCDs. The major health care workers in Healthy lifestyle Centers (HLC) include Medical Officers (MO), Nursing Officers (NO), Public Health Nursing Officers (PHNO), Public Health Midwife (PHM), and supportive staff members. Out of them, MOs, NOs, and PHNOs are three important HCW employed at HLC with regard to a major portion of service delivery on non-communicable diseases (NCDs). They are trained to carry out special activities for purpose of screening and providing lifestyle modification counseling for risk factors of NCD such as promotion of physical activity and healthy diet, tobacco cessation counseling. This requires knowledge and skills which need to be provided through in-service training programs. There are few training programs for $\mathrm{HCW}$ conducted by the Ministry of Health including six months of orientation training for PHNO at recruitment and one-week training for NO who are designated to work at HLC [3].

Training needs analysis (TNA) is an important Human resource management activity, which investigates gaps in the training program with desired performance outcome of trainees in a methodical way focusing heavily on the ability of the trainee and their support networks [4]. The identification of training needs must be resolved before training can be usefully undertaken. Training needs should be assessed by using a scientific method. Out of the methods available for this purpose, Hennessy-Hicks Training Needs 
Analysis (TNA) questionnaire is one of the extensively used validated instruments which is endorsed by the World Health Organization [5,6].

Medical officers and Nursing Officers constitute the main professional groups in each level of health care delivery service provision island nation-wide [7] (WHO,2019). A well-trained and skilled health workforce is vital to the delivery of efficient and effective care that is evidence-based. This has necessitated adopting a structured approach to the training needs assessment (TNA) in order to identify the development needs of the health professionals in process of producing a skilled workforce [8]. Health care workers with proper training will improve the quality-of-service provision which will eventually enhance the health status of the population [9].Currently implemented training need assessments are mostly created based on the need for funding sources in order to maintain their increment provision schemes for HCW. Improving healthcare services through the identification of training needs of the HCW is merely being addressed through these assessments. Re-structuring the training program for HCW of HLC by introducing tailor-made training need assessments considering their job descriptions will improve their skill development process with the training sessions. Therefore, training need assessment is a timely intervention that will improve the services provided by the $\mathrm{HCW}$ at the Healthy lifestyle centers. This study was conducted in order to identify the training needs of the different categories of staff who are employed at HLCs.

\section{MATERIAL AND METHODS}

Study Design: A descriptive cross-sectional study

Study Setting: Selected Healthy Lifestyle Centers (HLCs) representing all districts of Sri Lanka.

Study Population: Major Healthcare workers i.e., Medical Officers, Nursing Officers, Public Health Nursing Officers, and other major staff attached to HLCs.

Study Duration: one month

Sample Size calculation: The final sample size was calculated using formula $n=Z^{2} P(1-P) / d^{2}[10]$. The expected proportion $(P)$ of individuals with adequate knowledge was taken as $50 \%$ due to unavailability of data which gave the largest sample size, $\mathrm{Z}$ was taken as 1.96 corresponding to a confidence interval of $95 \%$. A 125 HLCs were recruited by using purposive sampling in a manner to represent all the districts of the country. Total major staff employees attached to the selected HLCs were known i.e., 465, a finite correction was done to obtain the required sample size using the formula $=\mathrm{SS} /[1+\{(\mathrm{SS}-1) / \mathrm{Pop}\}][11]$ (Hansen and Hurwitz 1943). With consideration of the 5\% non-response rate, the final sample size was 132 .

Subjects \& selection method: All the major staff employees of the selected HLCs were listed. This was used as the sampling frame to randomly recruit 132 study participants using a simple random sampling technique by using a random number generating computer program. The recruited participants were contacted via online platforms such as e mail, WhatsApp, Viber, etc.

Data collection tool and data collection: A modified version of Hennessey Hicks TNA questionnaire was formulated after reviewing the literature, field visits, and key informant interviews with relevant stakeholders from health and non-health sectors. The questionnaire with 18 items was self-administered and inquired following in relation to activities pertaining to their job and participants gave a score for each item; How important the activity is to the successful performance of your job (the importance score) $(1=$ not at all important $10=$ very important); How well you currently perform that activity (the performance score) $(1=$ very poorly $10=$ very well $)$; Activity could be improved through training alone $(1=$ strongly disagree $10=$ strongly agree $)$. The activity could be improved through changes in the work system ( $1=$ strongly disagree $10=$ strongly agree). The face, content, and consensual validity of the questionnaire were ensured by reviewing it by a panel of experts. Data were collected by using a pre-tested self-administered questionnaire by the means of a google form via online platforms such as email, WhatsApp, Viber, etc. after obtaining informed written consent.

Statistical analysis: The data was analyzed using descriptive statistics. SPSS version 22 package was used for data analysis. The training needs i.e., the difference with regard to each item was found out by subtracting the performance score from the importance score. Then, the average difference score for each item was calculated. As per Hennessy-Hicks TNA, bigger the average difference score, greater the group's training need. These average difference scores were given rank order, i.e., the highest rank for highest average difference and the lowest rank for the lowest average difference in order to establish the group's training needs hierarchy. Average Scores based on respondents' scores were calculated for their preference for training (T) and change in the work system (S) separately for each item in the questionnaire. Under each item, the option which had received the highest average out of training (T)

www.scirj.org

(C) 2021, Scientific Research Journal

http://dx.doi.org/10.31364/SCIRJ/v9.i06.2021.P0621864

This publication is licensed under Creative Commons Attribution CC BY. 
or changes in the work system (S) was selected as the preferred option for that particular item [12, 13]. These calculations were done for the whole study sample as well as for subsamples i.e., MO, PHNO, and NO.

The status of training need among MOs on health education was compared with that of all other categories of the staff and the status of training need for breast examination among NOs was compared with the rest of the staff categories by using the chi-square test.

\section{RESULTS}

The sample consisted of 76 (63.3\%) Medical Officers, 21 (17.5\%) Nursing officers, 19 (15.8) Public health nursing officers, and 4 (3.4\%) other major HCW of Healthy Lifestyle Centers of Sri Lanka. The response rate was $91 \%$ with 120 respondents from all the districts. The majority of participants were from Matara $13(10.8 \%)$ and Badulla $13(10.8 \%)$ districts while minimum participation was from Kegalle 1(0.8\%) and Kilinochchi $1(0.8 \%)$ districts.

Participant's years of experience at Ministry of Health was mean 10.8 (SD=7.7), Median=7.50 (IQR=11) \& Mode= 5 (Range 0.4 to 35$)$, their years of service at current working station was mean 3.6 $(\mathrm{SD}=2.7)$, median=3.0 (IQR=3.0) \& mode=3.0 (ranging from 0.11 to 13 ) and their experience in HLC in years was mean=3.6 (SD=2.3), Median=3.0 (IQR=3.0) \& Mode=2.0 (0.3 to 8.0). The findings with regard to training needs in the entire sample are as follows (Table 1).

TABLE 1: The training needs, assigned training priority, summary measures for training \& system development and suitable intervention for each item of the allstaff categories $(\mathrm{n}=120)$.

\begin{tabular}{|c|c|c|c|c|c|}
\hline Item & $\begin{array}{l}\text { Difference } \\
\text { Mean (SD) }\end{array}$ & $\begin{array}{l}\text { Assigned } \\
\text { Rank }\end{array}$ & $\begin{array}{l}\text { Training (T) } \\
\text { Mean (SD) }\end{array}$ & $\begin{array}{c}\text { System } \\
\text { Development } \\
\text { Mean (SD) }\end{array}$ & $\begin{array}{c}\text { Suitable } \\
\text { Intervention } \\
\text { (T/S) }\end{array}$ \\
\hline Conducting special programs to clients on Physical activity & $1.8(2.5)$ & 01 & $8.1(2.2)$ & $8.4(1.9)$ & $\mathrm{S}$ \\
\hline Conducting special programs to clients on healthy diet & $1.6(2.4)$ & $\mathbf{0 2}$ & $8.3(2.1)$ & $8.4(1.9)$ & $\mathrm{S}$ \\
\hline Conducting brief interventions for tobacco cessation & $1.4(2.2)$ & $\mathbf{0 3}$ & $8.3(1.9)$ & $8.2(1.8)$ & $\mathrm{S}$ \\
\hline Conducting health education sessions & $1.2(2.1)$ & 04 & $8.3(2.1)$ & $8.4(1.9)$ & $\mathrm{S}$ \\
\hline Conducting Oral examination & $1.1(1.7)$ & 05 & $8.2(2.1)$ & $8.0(1.9)$ & $\mathrm{T}$ \\
\hline Checking distant vision using Snellen's chart & $1.0(2.1)$ & 06 & $8.1(2.3)$ & $7.9(2.5)$ & $\mathrm{T}$ \\
\hline Conducting breast examination & $0.9(1.5)$ & 07 & $8.2(2.1)$ & $7.9(2.3)$ & $\mathrm{S}$ \\
\hline $\begin{array}{l}\text { Measuring blood pressure using the digital blood pressure } \\
\text { machines }\end{array}$ & $0.8(1.9)$ & 08 & $8.2(2.3)$ & $8.1(2.0)$ & $\mathrm{T}$ \\
\hline Logistic management & $0.75(1.4)$ & 09 & $8.4(1.9)$ & $8.1(1.9)$ & $\mathrm{T}$ \\
\hline Client Registration & $0.7(1.6)$ & 10 & $8.3(2.2)$ & $8.7(1.7)$ & $\mathrm{S}$ \\
\hline Assisting follow up for patients who attended the HLC & $0.6(1.5)$ & 11 & $8.0(2.3)$ & $8.4(1.8)$ & S \\
\hline Filling information in the Personal Medical Record & $0.6(1.4)$ & 12 & $8.5(2.0)$ & $8.6(1.8)$ & $\mathrm{S}$ \\
\hline Conducting capillary blood testing for sugar and cholesterol & $0.6(1.3)$ & 13 & $8.5(2.1)$ & $8.4(1.8)$ & $\mathrm{T}$ \\
\hline $\begin{array}{l}\text { Taking anthropometric measurements, calculation of BMI, } \\
\text { waist/height ratio }\end{array}$ & $0.54(1.2)$ & 14 & $8.5(1.9)$ & $8.3(2.1)$ & $\mathrm{T}$ \\
\hline Accurate advice for patients on preparation for blood testing & $0.52(1.2)$ & 15 & $8.5(1.8)$ & $8.3(1.9)$ & $\mathrm{T}$ \\
\hline Basic interpretation of biochemical test results & $0.51(1.2)$ & 16 & $8.4(1.9)$ & $8.2(2.1)$ & $\mathrm{T}$ \\
\hline CVD risk assessment and interpretation & $0.4(1.3)$ & 17 & $8.4(2.2)$ & $8.4(1.9)$ & $\mathrm{T}$ \\
\hline Maintaining registers and compiling monthly return & $0.4(1.2)$ & 18 & $8.5(1.9)$ & $8.2(2.1)$ & $\mathrm{T}$ \\
\hline
\end{tabular}

The prioritized training needs were conducting special programs to clients on physical activity, conducting special programs to clients on healthy diet, conducting brief interventions for tobacco cessation, conducting health education sessions, and conducting oral 
examination. Out of these five prioritized activities among all categories of HCW, all could be improved through changes in the work system except for oral examination where the suggested intervention was training alone.

The training needs of the selected 18 items were assessed among Medical Officers. The prioritized training needs were conducting special programs to clients on a healthy diet, conducting special programs to clients on physical activity, conducting health education sessions, conducting brief interventions for tobacco cessation, and conducting oral examination. Medical Officers stated performance improvement of the prioritized activities can be done through changes in the work system . The finding of TNA among Medical Officers working in HLCs are as follows (Table 2).

TABLE 2: The training needs, assigned training priority, summary measures for training \& system development, and suitable intervention for each item of the Medical Officers ( $\mathrm{n}=76$ ).

\begin{tabular}{|c|c|c|c|c|c|}
\hline Item & $\begin{array}{l}\text { Difference } \\
\text { Mean (SD) }\end{array}$ & $\begin{array}{l}\text { Assigned } \\
\text { Rank }\end{array}$ & $\begin{array}{l}\text { Training (T) } \\
\text { Mean (SD) }\end{array}$ & $\begin{array}{c}\text { System } \\
\text { Development } \\
\text { Mean (SD) }\end{array}$ & $\begin{array}{c}\text { Suitable } \\
\text { Intervention } \\
\text { (T/S) }\end{array}$ \\
\hline Conducting special programs to clients on healthy diet & $1.98(2.59)$ & 01 & $8.24(2.01)$ & $8.5(1.62)$ & $\mathrm{S}$ \\
\hline Conducting special programs to clients on Physical activity & $1.97(2.65)$ & 02 & $8.01(2.05)$ & $8.52(1.59)$ & $\mathrm{S}$ \\
\hline Conducting health education sessions & $1.63(2.30)$ & $\mathbf{0 3}$ & $8.23(1.93)$ & $8.54(1.57)$ & S \\
\hline Conducting brief interventions for tobacco cessation & $1.58(2.48)$ & 04 & $8.27(1.84)$ & $8.45(1.61)$ & $\mathrm{S}$ \\
\hline Conducting Oral examination & $1.33(1.96)$ & 05 & $8.04(2.12)$ & $8.16(1.76)$ & $\mathrm{S}$ \\
\hline Checking distant vision using Snellen's chart & $1.14(2.05)$ & 06 & $8.09(2.19)$ & $8.20(2.02)$ & $S$ \\
\hline Conducting breast examination & $1.09(1.59)$ & 07 & $8.06(1.98)$ & $8.08(2.00)$ & $\mathrm{S}$ \\
\hline $\begin{array}{l}\text { Measuring blood pressure using the digital blood pressure } \\
\text { machines }\end{array}$ & $1.01(2.12)$ & 08 & $8.05(2.38)$ & $8.31(1.87)$ & S \\
\hline Client Registration & $0.79(1.55)$ & 09 & $8.23(2.19)$ & $8.79(1.61)$ & $\mathrm{S}$ \\
\hline Assisting follow up for patients who attended the HLC & $0.71(1.50)$ & 10 & $7.94(2.09)$ & $8.59(1.71)$ & $\mathrm{S}$ \\
\hline Logistic management & $0.68(1.16)$ & 11 & $8.44(1.80)$ & $8.20(1.91)$ & $\mathrm{T}$ \\
\hline Accurate advice for patients on preparation for blood testing & $0.67(1.40)$ & 12 & $8.50(1.70)$ & $8.24(1.87)$ & $\mathrm{T}$ \\
\hline Filling information in the Personal Medical Record & $0.63(1.28)$ & 13 & $8.35(2.03)$ & $8.59(1.75)$ & $S$ \\
\hline Conducting capillary blood testing for sugar and cholesterol & $0.56(1.28)$ & 14 & $8.60(1.97)$ & $8.56(1.72)$ & $\mathrm{T}$ \\
\hline $\begin{array}{l}\text { Taking anthropometric measurements, calculation of BMI, } \\
\text { waist/height ratio }\end{array}$ & $0.54(1.16)$ & 15 & $8.43(1.82)$ & $8.59(1.71)$ & S \\
\hline Basic interpretation of biochemical test results & $0.51(1.25)$ & 16 & $8.50(1.76)$ & $8.44(1.85)$ & $\mathrm{T}$ \\
\hline CVD risk assessment and interpretation & $0.44(1.17)$ & 17 & $8.40(2.09)$ & $8.50(1.71)$ & $\mathrm{S}$ \\
\hline Maintaining registers and compiling monthly return & $0.43(0.99)$ & 18 & $8.47(1.85)$ & $8.28(1.93)$ & $\mathrm{T}$ \\
\hline
\end{tabular}

Among Public Health Nursing Officers (PHNOs), the prioritized training needs are conducting special programs to clients on Physical activity, conducting brief interventions for tobacco cessation, conducting oral examination, Logistic management, and conducting special programs to clients on healthy diet. They stated performance improvement of the prioritized activities through training alone. The finding of TNA among PHNOs in HLCs are as follows (Table 3). 
TABLE 3: The training needs, assigned training priority, summary measures for training \& system development, and suitable intervention for each item of the PHNO $(n=19)$.

\begin{tabular}{|c|c|c|c|c|c|}
\hline Item & $\begin{array}{l}\text { Difference } \\
\text { Mean (SD) }\end{array}$ & $\begin{array}{l}\text { Assigned } \\
\text { Rank }\end{array}$ & $\begin{array}{l}\text { Training (T) } \\
\text { Mean (SD) }\end{array}$ & $\begin{array}{c}\text { System } \\
\text { Development } \\
\text { Mean (SD) }\end{array}$ & $\begin{array}{c}\text { Suitable } \\
\text { Intervention } \\
\text { (T/S) }\end{array}$ \\
\hline Conducting special programs to clients on Physical activity & $2.21(2.85)$ & 01 & $8.15(2.47)$ & $7.63(2.49)$ & $\mathrm{T}$ \\
\hline Conducting brief interventions for tobacco cessation & $1.63(2.29)$ & $\mathbf{0 2}$ & $8.36(2.16)$ & $7.73(2.28)$ & $\mathrm{T}$ \\
\hline Conducting Oral examination & $1.57(2.79)$ & $\mathbf{0 3}$ & $8.47(1.86)$ & $7.68(2.28)$ & $\mathrm{T}$ \\
\hline Logistic management & $1.56(2.47)$ & 04 & $8.36(2.16)$ & $8.05(2.06)$ & $\mathrm{T}$ \\
\hline Conducting special programs to clients on healthy diet & $1.52(2.48)$ & 05 & $8.73(2.20)$ & $8.15(2.33)$ & $\mathrm{T}$ \\
\hline Checking distant vision using Snellen's chart & $1.36(3.11)$ & 06 & $7.84(2.54)$ & $6.68(3.03)$ & $\mathrm{T}$ \\
\hline Filling information in the Personal Medical Record & $1.05(2.14)$ & 07 & $8.52(2.34)$ & $8.31(2.28)$ & $\mathrm{T}$ \\
\hline Client Registration & $0.94(2.27)$ & 08 & $8.21(2.89)$ & $8.05(2.39)$ & $\mathrm{T}$ \\
\hline Assisting follow up for patients who attended the HLC & $0.84(2.14)$ & 09 & $7.89(2.99)$ & $8.05(2.27)$ & S \\
\hline $\begin{array}{l}\text { Taking anthropometric measurements, calculation of BMI, } \\
\text { waist/height ratio }\end{array}$ & $0.78(2.09)$ & 10 & $8.47(2.54)$ & $7.84(2.60)$ & $\mathrm{T}$ \\
\hline CVD risk assessment and interpretation & $0.77(2.14)$ & 11 & $8.63(2.21)$ & $8.26(1.88)$ & $\mathrm{T}$ \\
\hline Conducting health education sessions & $0.77(1.87)$ & 12 & $8.42(2.73)$ & $8.10(2.33)$ & $\mathrm{T}$ \\
\hline Basic interpretation of biochemical test results & $0.73(1.99)$ & 13 & $8.26(2.05)$ & $8.00(1.88)$ & $\mathrm{T}$ \\
\hline $\begin{array}{l}\text { Measuring blood pressure using the digital blood pressure } \\
\text { machines }\end{array}$ & $0.68(1.82)$ & 14 & $7.84(2.91)$ & $7.42(2.98)$ & $\mathrm{T}$ \\
\hline Conducting breast examination & $0.63(1.67)$ & 15 & $8.42(2.45)$ & $7.63(2.67)$ & $\mathrm{T}$ \\
\hline Conducting capillary blood testing for sugar and cholesterol & $0.62(1.89)$ & 16 & $8.21(2.43)$ & $8.05(2.17)$ & $\mathrm{T}$ \\
\hline Accurate advice for patients on preparation for blood testing & $0.52(1.38)$ & 17 & $8.52(2.19)$ & $8.15(2.38)$ & $\mathrm{T}$ \\
\hline Maintaining registers and compiling monthly return & $0.50(2.06)$ & 18 & $8.73(2.20)$ & $7.89(2.78)$ & $\mathrm{T}$ \\
\hline
\end{tabular}

The training needs prioritized areas for Nursing Officers were conducting special programs to clients on Physical activity, conducting breast examination, conducting oral examination, conducting special programs to clients on healthy diet and Logistic management. They prefer to learn prioritized areas by taught courses except conducting special programs to clients on Physical activity. They stated that all could be improved through changes in the work system. The finding of TNA among Nursing Officers in HLCs are as follows (Table 4). 
TABLE 4: The training needs, assigned training priority, summary measures for training \& system development, and suitable intervention for each item of the Nursing Officers $(\mathrm{n}=21)$.

\begin{tabular}{|c|c|c|c|c|c|}
\hline Item & $\begin{array}{l}\text { Difference } \\
\text { Mean (SD) }\end{array}$ & $\begin{array}{l}\text { Assigned } \\
\text { Rank }\end{array}$ & $\begin{array}{l}\text { Training (T) } \\
\text { Mean (SD) }\end{array}$ & $\begin{array}{c}\text { System } \\
\text { Development } \\
\text { Mean (SD) }\end{array}$ & $\begin{array}{c}\text { Suitable } \\
\text { Intervention } \\
\text { (T/S) }\end{array}$ \\
\hline $\begin{array}{l}\text { Conducting special programs to clients on Physical } \\
\text { activity }\end{array}$ & $1.33(1.71)$ & 01 & $8.47(2.04)$ & $8.61(1.65)$ & $\mathrm{S}$ \\
\hline Conducting breast examination & $1.04(1.20)$ & 02 & $8.85(1.52)$ & $7.57(2.63)$ & T \\
\hline Conducting Oral examination & $0.90(1.33)$ & 03 & $8.95(1.35)$ & $8.04(1.85)$ & $\mathrm{T}$ \\
\hline Conducting special programs to clients on healthy diet & $0.71(1.18)$ & 04 & $8.38(2.17)$ & $8.19(1.91)$ & T \\
\hline Logistic management & $0.70(1.30)$ & 05 & $8.54(2.22)$ & $8.00(2.36)$ & T \\
\hline Conducting brief interventions for tobacco cessation & $0.66(1.19)$ & 06 & $8.42(1.53)$ & $8.23(1.60)$ & T \\
\hline $\begin{array}{l}\text { Measuring blood pressure using the digital blood } \\
\text { pressure machines }\end{array}$ & $0.61(1.77)$ & 07 & $8.90(1.37)$ & $8.19(1.96)$ & T \\
\hline Checking distant vision using Snellen's chart & $0.47(0.92)$ & 08 & $8.61(2.15)$ & $7.95(2.95)$ & T \\
\hline $\begin{array}{l}\text { Conducting capillary blood testing for sugar and } \\
\text { cholesterol }\end{array}$ & $0.46(1.16)$ & 09 & $8.76(2.11)$ & $8.33(2.24)$ & T \\
\hline $\begin{array}{l}\text { Taking anthropometric measurements, calculation of } \\
\text { BMI, waist/height ratio }\end{array}$ & $0.42(0.59)$ & 10 & $8.90(1.84)$ & $7.71(2.88)$ & T \\
\hline Basic interpretation of biochemical test results & $0.38(0.58)$ & 11 & $8.76(1.84)$ & $7.90(2.54)$ & T \\
\hline Conducting health education sessions & $0.38(0.74)$ & 12 & $8.66(1.71)$ & $8.23(1.78)$ & T \\
\hline Assisting follow up for patients who attended the HLC & $0.38(0.66)$ & 13 & $8.90(1.81)$ & $8.28(2.07)$ & T \\
\hline Client Registration & $0.33(0.65)$ & 14 & $8.47(1.99)$ & $9.04(1.32)$ & S \\
\hline Maintaining registers and compiling monthly return & $0.33(0.65)$ & 15 & $8.57(2.31)$ & $8.04(2.33)$ & T \\
\hline Filling information in the Personal Medical Record & $0.28(0.64)$ & 16 & $8.85(1.87)$ & $8.71(1.73)$ & S \\
\hline CVD risk assessment and interpretation & $0.14(0.35)$ & 17 & $8.76(2.16)$ & $8.09(2.09)$ & T \\
\hline $\begin{array}{l}\text { Accurate advice for patients on preparation for blood } \\
\text { testing }\end{array}$ & $0.04(0.21)$ & 18 & $8.85(1.85)$ & $8.28(2.30)$ & T \\
\hline
\end{tabular}

Out of five prioritized training needs, conducting health education sessions for Medical Officers and conducting breast examinations for Nursing Officers were unique for these two HCW categories. The association of having a training need and belonging to one $\mathrm{HCW}$ category against the rest of the $\mathrm{HCW}$ categories were determined (Table 5). 
TABLE 5: Status of training need and the healthcare worker category.

\begin{tabular}{|c|c|c|c|c|}
\hline \multirow[t]{3}{*}{ Category } & \multicolumn{2}{|c|}{ Status of training need } & \multirow{3}{*}{ Total } & \multirow{3}{*}{ Statistic } \\
\hline & \multicolumn{2}{|c|}{ On Health Education } & & \\
\hline & Yes & No & & \\
\hline Medical Officers & $43(79.6 \%)$ & $11(20.4 \%)$ & $54(100.0 \%)$ & $\mathrm{OR}=4.4$ \\
\hline & & & & $(95 \% \mathrm{Cl}=1.9-10.0)$ \\
\hline \multirow{4}{*}{$\begin{array}{l}\text { Other categories of } \\
\text { staff }\end{array}$} & 31 (470\%) & $35(530 \%)$ & $66(1000 \%)$ & $X 2=13.4$ \\
\hline & & & $00(100.0 \%)$ & $\mathrm{Df}=1$ \\
\hline & \multicolumn{2}{|c|}{ Breast Examination } & & \\
\hline & Yes & No & & \\
\hline \multirow[t]{2}{*}{ Nursing Officers } & $09(42.9 \%)$ & $12(57.1 \%)$ & $21(100.0 \%)$ & $\mathrm{OR}=0.9$ \\
\hline & & & & $(95 \% \mathrm{Cl}=0.3-2.3)$ \\
\hline \multirow{3}{*}{$\begin{array}{l}\text { Other categories of } \\
\text { the staff }\end{array}$} & $45(45.5 \%)$ & $54(54.5 \%)$ & $99(100.0 \%)$ & $x 2=0.47$ \\
\hline & & & & $D f=1$ \\
\hline & & & & $P=0.828$ \\
\hline
\end{tabular}

Being a Medical Officer had 4.4 times need of training in health education compared to other HCW categories and this association was statistically significant at $\mathrm{p}=0.05$. in contrast, 'being a Nursing Officer' or 'not' was not associated with the status of training need to perform breast examination.

\section{DISCUSSION}

The Hennessy-Hicks Training Need Assessment questionnaire is a tool which had been used throughout the world to evaluate the training requirements of healthcare workers. The findings could be used to prioritize education and development in a manner that meets local needs. This questionnaire had been used in different settings across the globe in order to assess the training needs across the globe and it had been recognized as a valid tool by the World Health Organization [12]. The questions were conceptualized in a manner that covers the whole spectrum of services provided by HCW of the HLC by triangulating the information through literature and expert opinions. This questionnaire was translated into Sinhala and Tamil languages by using forward and backward translation techniques. Its judgmental validity was ensured by assessing face, content, and consensual validity by a panel of experts comprised of public health experts and educationists. The questionnaire was pretested prior to administration into the study sample. These measures were taken in order to minimize information bias.

Healthy Lifestyle centers are established for screening of NCDs and risk factors. Identification of the training needs of HCWs' could be considered vital to optimize the services rendered to its clients. A representative sample of HCW has been recruited and this could allow extrapolating the results of this study into the source population.

As per the user manual of the tool, higher the values of the average scores of the difference between the importance score and performance score, the priority for such training area is high. This principle was valuable in the identification of the training need priorities. Identification of training needs in a prioritized manner in advance would be helpful in designing in-service training programs cost-effectively. Furthermore, these training needs will be used in the development of basic training curricular for the HCW by the Ministry of Health.

Training need for physical activity, healthy diet, and oral examination across all the staff categories as a priority could be considered as an important finding of the present study. Since physical inactivity and an unhealthy diet are considered the main risk factors for NCDs, the ability of the staff to promote physical activity and diet could be considered vital. Training need in physical activities among doctors had been identified in global literature as well [14].

Similarly, training all of them on how to conduct oral examination will lead the path to identify one of the commonest cancers in Sri Lanka early i.e., oral cancer. Cessation of tobacco use is one of the interventions that could be implemented at HLCs for their clients. Conducting brief interventions for tobacco cessation had been identified as a training need among Medical Officers as well as Public Health Nursing Officers.

Maintenance of the supply chain at the HLC could be considered as key to the uninterrupted provision of services. The PHNOs and NOs who are mainly involved with this process have identified stock management as a priority service need.

For the majority of the training needs identified, PHNOs and NOs have identified attending teaching sessions would be the solution in contrast to MOs view i.e., changes in the systems.

www.scirj.org

(C) 2021, Scientific Research Journal

http://dx.doi.org/10.31364/SCIRJ/v9.i06.2021.P0621864

This publication is licensed under Creative Commons Attribution CC BY. 


\section{CONCLUSION AND RECOMMENDATIONS}

There are training needs at different intensities among healthcare workers. Preparation of training programs/interventions tailormade to address these priorities health needs will serve the purpose.

\section{ACKNOWLEDGMENT}

We would thank authors of the questionnaire (Hennessy, D.A. and Hicks, C.M.), the UoB, and WHO, all the MO-NCDs in Sri Lanka and all the study participants.

\section{REFERENCES}

[1] Gaspard J, Yang C-M. Training needs assessment of health care professionals in a developing country: the example of Saint Lucia. BMC medical education. 2016;16(1):1-6.

[2] Dessler G. Fundamentals of human resource management. Pearson; 2013.

[3] WHO. Public Health Sucess in Sri Lanka [Internet]. 2016. Available from: https://apps.who.int/iris/rest/bitstreams/1081775/retrieve

[4] Carlisle J, Bhanugopan R, Fish A. Training needs of nurses in public hospitals in Australia. Journal of European Industrial Training. 2011;

[5] Markaki A, Malhotra S, Billings R, Theus L. Training needs assessment: tool utilization and global impact. BMC Medical Education. 2021;21(1):1-20.

[6] Hennessy D, Hicks C. A cross - cultural tool to identify continuing education needs. International nursing review. 1998;45(4):109 - 14.

[7] World Health Organization. WHO Sri Lanka Biennium Report 2018-2019. 2019;

[8] Prammanee N. Need assessment techniques for developing an effective training program. HRD Journal. 2015;6(1):9-26.

[9] Mallawaarachchi DV, Wickremasinghe SC, Somatunga LC, Siriwardena VT, Gunawardena NS. Healthy Lifestyle Centres: a service for screening noncommunicable diseases through primary health-care institutions in Sri Lanka. WHO South-East Asia journal of public health. 2016;5(2):89-95.

[10] Lwanga SK, Lemeshow S, World Health Organization. Sample size determination in health studies: a practical manual. World Health Organization; 1991.

[11] Hansen MH, Hurwitz WN. On the theory of sampling from finite populations. The Annals of Mathematical Statistics. $1943 ; 14(4): 333-62$.

[12] Hicks C. Hennessy-Hicks training needs analysis questionnaire and manual. Birmingham University Licensed to WHO for On-line use:< http://www who int/workforcealliance/knowledge/HennessyHicks_trainingneedstool pdf> No date Accessed in April. 2011;3.

[13] Martilla JA, James JC. Importance-performance analysis. Journal of marketing. 1977;41(1):77-9.

[14] Gates AB. Training tomorrow's doctors, in exercise medicine, for tomorrow's patients. 2015; 